\title{
Tumor Macroenvironment: An Update
}

\author{
Wael Al-Zoughbi Gerald Hoefler \\ Diagnostic and Research Institute of Pathology, Medical University of Graz, Graz, Austria
}

\section{Keywords}

Cell-cell interaction · Tumor environment · Malignant growth

\begin{abstract}
Modes of tumor cell interaction include autocrine stimulation, secretion of paracrine growth factors and inhibitors, as well as interaction with the tumor macroenvironment. This evolving concept in tumor pathobiology describes the interaction of a malignant tumor with its host as an extension and addition to its local interaction with tumor cells and surrounding nontransformed cells, the tumor microenvironment. Angiogenesis, which is considered part of the tumor microenvironment, also allows reciprocal interactions between cancer cells and other organs and systems. Wellknown examples of tumor endocrine signaling are the paraneoplastic syndromes. In addition, cachexia, a severe complication of tumor growth, results from the systemic reprogramming of the host metabolism as a result of tumor growth and progression. Moreover, recent reports indicate that cancer cells may secrete factors that might play a role in forming premetastatic niches at distant sites. In addition, cancer cells seem to be able to secrete factors influencing and resetting endogenous circadian organizers. The importance of understanding the whole complex interaction of a malignant tumor and its host - the tumor macroenvironment - is of great importance for the better management and treatment of cancer patients.

(c) 2019 S. Karger AG, Basel
\end{abstract}

(C) 2019 S. Karger AG, Basel

www.karger.com/pat

Karger"
Among all the abnormalities in cell physiology that characterize malignant growth, one hallmark stands out, which has been confirmed in all types of cancer cells - dysregulated cell-cell interaction. We have introduced the concept of tumor macroenvironment as an additional solid basis for understanding the complexity of cancer pathobiology as a result of the underlying genetic alterations and beyond the local interaction with non-tumor cells within the tumor microenvironment. This concept has been accepted, is evolving and is expanded in the following.

In a multicellular organism, intercellular signaling is critical for development and survival. This holds true also for cancer as an intricate complex of disturbances. While cellular homeostasis in unicellular organisms is regulated through intra- and extracellular adaptations, the fact that in multicellular organisms cells require to interact and adapt to changes and signals from the macroenvironment highlights the importance of the macroenvironment concept when considering cancer pathobiology. The initial step for the understanding of this abnormal interaction is to distinguish between three highly consequential types of interactions forming and constantly changing the tumor environment. The types of cells which send and receive signals and the spatial distribution of this cellular signaling are the basic principles behind the differences between the main three types of intercellular interactions. It is of the highest interest to emphasize the importance of interpreting cancer as an aggregation of transformed (malignant) and nontransformed cells - a tissue-like 
structure - and to draw a line between this term and an organ.

Todaro and De Larco [1] were among the first to discover that cancer cells release ligands that bind to receptors on their own surface as an important process for cancer growth - the first type of interaction. It is now well known that the operation of this extracellular loop of the autocrine mechanism is associated with independency of exogenous growth factors providing tumor cells with a pathological, autonomous behavior [2-4]. Although still controversial, there are data suggesting that intracellular activation of receptors by autocrine mechanisms may play a role in cell transformation, "the private loop" $[3,5]$. There has been a gigantic increase in knowledge about the way tumor microenvironmental factors control the growth of cancer and about the way tumor cells respond to these local paracrine growth factors and inhibitors the second type of interaction. In fact, this kind of signaling characterizes the tumor microenvironment. In contrast, the importance of understanding the tumor macroenvironment has just recently been appreciated as the third type of interaction [6-14]. In solid malignancies, tumor-associated neovasculature is a critical step in cancer growth and progression. Our current understanding is that the process of angiogenesis allows reciprocal interactions between cancer cells and other organs and systems. It is evident that the presence or absence of the tumor-associated neovasculature is critical for the third type of interaction, endocrine signaling.

Classical examples for tumor endocrine signaling are paraneoplastic syndromes. These disorders arise from tumor secretion of various factors and are associated with specific types of malignancies [15]. Although rare, they are well characterized and studied because of the direct relevance to the clinic [16]. In addition to the paraneoplastic syndromes, it appears appropriate to mention here that the recent literature on tumor and homeostasis has confirmed the importance of understanding the whole complex of disturbance in cancer patients - the tumor macroenvironment - for better management and treatment [17-22].

It has now been shown that cachexia is not only a severe complication of tumor growth but results from the systemic metabolic reprogramming of the host as a result of tumor growth and progression [23]. Recent data demonstrated that tumor cytokine expression profiles differ between cachectic and weight-stable cancer patients diagnosed with the same type of cancer and emphasize the crosstalk between the tumor and peripheral tissues [24]. Castellani et al. [25] studied the effects of tumor growth on systemic metabolic changes by xenografting human neuroblastoma cells into mice and could show that these cells caused a catabolic proinflammatory state in the animals. A study on human glioma cells highlighted the importance of external amino acids to support the survival and propagation of cancer cells via the epidermal growth factor receptor [26]. A recent report showed that cancer cell-secreted insulin-like growth factor 2 regulates vascular endothelial growth factor in bone marrow cells and suggests that this might play a role in forming premetastatic niches at distant sites [27]. You et al. [28] suggest that polyunsaturated fatty acid levels in the tumor macroenvironment might play a role in the predisposition for breast carcinogenesis and metastasis. This will be of great importance for breast cancer treatment and prevention if validated. The striking results obtained by Masri et al. [29] and Masri and Sassone-Corsi [30] illustrated a previously unappreciated role played by lung adenocarcinoma as an endogenous circadian organizer in the rewiring of circadian homeostasis of the liver. Another important observation regarding the tumor macroenvironment and the biological clock in cancer was made by de Assis et al. [31]. The authors used a nonmetastatic melanoma model and found that the molecular clocks of lungs and liver, and the suprachiasmatic nucleus were significantly affected by the tumor [31].

Cancer is one of the chronic diseases where physiological and regulatory processes between diseased cells and their environment are not just lost but rather result in pathological interactions. In this update, we have attempted to acquaint the reader with the current state of knowledge on the tumor macroenvironment as an evolving concept in cancer pathobiology. Based on these new data and points of view we hope that the tumor macroenvironment will receive further recognition and sufficient investigation.

\section{Disclosure Statement}

The authors have no conflicts of interest to disclose. 


\section{References}

1 Todaro GJ, De Larco JE. Growth factors produced by sarcoma virus-transformed cells. Cancer Res. 1978 Nov;38(11 Pt 2):4147-54.

2 Todaro GJ, Fryling C, De Larco JE. Transforming growth factors produced by certain human tumor cells: polypeptides that interact with epidermal growth factor receptors. Proc Natl Acad Sci USA. 1980 Sep;77(9):5258-62.

3 Keating MT, Williams LT. Autocrine stimulation of intracellular PDGF receptors in vsis-transformed cells. Science. 1988 Feb; 239(4842):914-6.

4 Nicolson GL. Paracrine/autocrine growth mechanisms in tumor metastasis. Oncol Res. 1992;4(10):389-99.

5 Browder TM, Dunbar CE, Nienhuis AW. Private and public autocrine loops in neoplastic cells. Cancer Cells. 1989;1:9-17.

6 Castaño Z, Tracy K, McAllister SS. The tumor macroenvironment and systemic regulation of breast cancer progression. Int J Dev Biol. 2011;55(7-9):889-97.

7 Al-Zoughbi W, Huang J, Paramasivan GS, Till H, Pichler M, Guertl-Lackner B, et al. Tumor macroenvironment and metabolism. Semin Oncol. 2014 Apr;41(2):281-95.

8 Becker JC. Tumor-educated myeloid cells: impact the micro- and macroenvironment. Exp Dermatol. 2014 Mar;23(3):157-8.

9 Erdman SE, Poutahidis T. The microbiome modulates the tumor macroenvironment. OncoImmunology. 2014 Mar;3(3):e28271.

10 Javeed N, Sagar G, Dutta SK, Smyrk TC, Lau JS, Bhattacharya S, Truty M, Petersen GM, Kaufman RJ, Chari ST, Mukhopadhyay D. Pancreatic cancer-derived exosomes cause paraneoplastic beta-cell dysfunction. Clin Cancer Res. 2015;21:1722-1733.

11 Javeed N, Mukhopadhyay D. Exosomes and their role in the micro-/macro-environment: a comprehensive review. J Biomed Res. 2017 Sep;31(5):386-94.

12 Bhat R, Bissell MJ. Of plasticity and specificity: dialectics of the microenvironment and macroenvironment and the organ phenotype. Wiley Interdiscip Rev Dev Biol. 2014 MarApr;3(2):147-63.

13 Sverdlov ED. Multidimensional Complexity of Cancer. Simple Solutions Are Needed. Biochemistry (Mosc). 2016 Jul;81(7):731-8.
14 Laplane L, Duluc D, Larmonier N, Pradeu T, Bikfalvi A. The Multiple Layers of the Tumor Environment. Trends Cancer. 2018 Dec; 4(12):802-9.

15 Rodríguez PL, Yurgaky SJ, Otero RW, Faizal M. Síndromes paraneoplásicos en tumores gastrointestinales. Revisión de tema. Rev Colomb Gastroenterol. 2017;32(3):230-44.

16 Pelosof LC, Gerber DE. Paraneoplastic syndromes: an approach to diagnosis and treatment. Mayo Clin Proc. 2010 Sep;85(9):838-54.

17 Bredell MG, Ernst J, El-Kochairi I, Dahlem Y, Ikenberg K, Schumann DM. Current relevance of hypoxia in head and neck cancer. Oncotarget. 2016 Aug;7(31):50781-804.

18 Decio A, Cesca M, Bizzaro F, Porcu L, Bettolini R, Ubezio P, et al. Cediranib combined with chemotherapy reduces tumor dissemination and prolongs the survival of mice bearing patient-derived ovarian cancer xenografts with different responsiveness to cisplatin. Clin Exp Metastasis. 2015 Oct;32(7):647-58.

19 Ocana MC, Martinez-Poveda B, Quesada AR, Medina MA. Metabolism within the tumor microenvironment and its implication on cancer progression: an ongoing therapeutic target. Med Res Rev. 2019;39(1):70-113.

20 Till H, Schlichting N, Oberbach A. Tumorassociated energy homeostasis: hepatoblastoma and neuroblastoma affect glucose and lipid metabolism as well as ghrelin, GLP-1, and PYY in nude rats. Eur J Pediatr Surg/Z Kinderchir. 2015;25:128-31.

21 Posch F, Pichler M. Inflammatory Biomarkers in Diffuse Large B-Cell Lymphoma: Time for Extending the Established Prognosis Scores? Acta Haematol. 2017;137(2):73-5.

22 Barth DA, Riedl JM, Posch F, Smolle MA, Kasparek AK, Niedrist T, Szkandera J, Stoger H, Pichler M, Stotz M, Gerger A. Critical evaluation of platelet size as a prognostic biomarker in colorectal cancer across multiple treatment settings: a retrospective cohort study. Clin Transl Oncol. 2019;21(8):1034-43.

23 Porporato PE. Understanding cachexia as a cancer metabolism syndrome. Oncogenesis. 2016 Feb;5(2):e200.
24 de Matos-Neto EM, Lima JD, de Pereira WO, Figuerêdo RG, Riccardi DM, Radloff K, et al. Systemic inflammation in cachexia: is tumor cytokine expression profile the culprit? Front Immunol. 2015 Dec;6:629.

25 Castellani C, Singer G, Kaiser M, Kaiser T, Huang J, Sperl D, et al. Neuroblastoma causes alterations of the intestinal microbiome, gut hormones, inflammatory cytokines, and bile acid composition. Pediatr Blood Cancer. 2017 Aug;64(8):64.

26 Tsuchihashi K, Okazaki S, Ohmura M, Ishikawa M, Sampetrean O, Onishi N, Wakimoto $\mathrm{H}$, Yoshikawa M, Seishima R, Iwasaki Y, Morikawa T, Abe S, Takao A, Shimizu M, Masuko T, Nagane M, Furnari FB, Akiyama T, Suematsu M, Baba E, Akashi, Koichi, Saya H, Nagano $\mathrm{O}$. The EGF receptor promotes the malignant potential of glioma by regulating amino acid transport system xc(-). Cancer Res. 2016;76(10).2954-63.

27 Xu WW, Li B, Guan XY, Chung SK, Wang Y, Yip YL, et al. Cancer cell-secreted IGF2 instigates fibroblasts and bone marrow-derived vascular progenitor cells to promote cancer progression. Nat Commun. 2017 Feb;8(1): 14399.

28 You S, Tu H, Zhao Y, Liu Y, Chaney EJ, Marjanovic M, et al. Raman Spectroscopic Analysis Reveals Abnormal Fatty Acid Composition in Tumor Micro- and Macroenvironments in Human Breast and Rat Mammary Cancer. Sci Rep. 2016 Sep;6(1):32922.

29 Masri S, Papagiannakopoulos T, Kinouchi K, Liu Y, Cervantes M, Baldi P, et al. Lung Adenocarcinoma Distally Rewires Hepatic Circadian Homeostasis. Cell. 2016 May;165(4): 896-909.

30 Masri S, Sassone-Corsi P. The emerging link between cancer, metabolism, and circadian rhythms. Nat Med. 2018 Dec;24(12):1795803

31 de Assis LVM, Moraes MN, et al. Non-metastatic cutaneous melanoma induces chronodisruption in central and peripheral circadian clocks. Int J Mol Sci. 2018;19(4): E1065. 